\title{
ON UNSATURATED SOIL MECHANICS - PERSONAL VIEWS ON CURRENT RESEARCH
}

\author{
G.N. PANDE \\ Zienkiewicz Centre for Computational Engineering, Swansea University, Swansea, UK
}

\section{S. PIETRUSZCZAK}

Department of Civil Engineering, McMaster University, Hamilton, Canada

\begin{abstract}
This paper presents the authors' personal views on current research being conducted by various research groups around the world in the broad area of mechanics of unsaturated geomaterials in general and soils in particular. The topic is of interest to a wide spectrum of scientists and engineers working in diverse areas such as geology and geophysics, powder technology, agricultural, petroleum, chemical, geotechnical, civil, environmental and nuclear engineering. Even if we restrict ourselves to civil, geotechnical and environmental engineering, it is noted that a plethora of hypotheses as well as a number of empirical and semiempirical relations have been introduced for describing the mechanics of unsaturated porous media. However, many of these proposed advances as well as methods of testing may lack sound theoretical basis.
\end{abstract}

Key words: unsaturated soil, suction, microstructure of saturation, constitutive relation

\section{INTRODUCTION}

The topic of hydro-mechanical behaviour of unsaturated soils has attracted a lot of attention as it is important for the analysis, design and long-term performance of underground structures which are being planned or constructed in many countries for storage of oils and gases, disposal of nuclear waste and sequestration of carbon dioxide. National Research Councils and industry of many countries have funded research in this area for the past 15 years, during which hundreds of research papers have been published in the proceedings of conferences and reputed international journals. Many theories to characterise the mechanical response, methodologies for laboratory testing as well as equipment to determine the constitutive parameters have been developed. Instruments to study in-situ behaviour of unsaturated soils have also been promoted and used in a few cases. A number of text books dedicated to mechanics of unsaturated soils have been published ([1]-[3]). Most publications attempt to extend standard soil mechanics and its long-established fundamental principle of 'effective stress' for 'saturated' soils to 'unsaturated' soils. It is worthy to note that until recently most text books (e.g., [4], [5]) hardly had any information on unsaturated soils. However, this topic is of immense practical importance and should be adequately addressed.

It is admitted that an accurate description of mechanical response of unsaturated soils requires some additional physical parameters but these seem to have been chosen rather arbitrarily. Additional adhoc hypotheses have also been introduced by numerous researchers in a bid to match experimentally observed response with that obtained from their proposed theories. The authors assert in this paper that the condition of partial saturation in soil does not imply a new type of soil for which one will need new theories or parameters. In proposing new theories and hypotheses, the researchers seem to have overlooked the Occam's ${ }^{1}$ Principle which states: 'Entities should not be multiplied unnecessarily' (in its original Latin form 'Pluralitas non est ponenda sine neccesitate'). The logic behind the principle is that new theories/hypotheses, if proposed without proper scrutiny, may contradict the existing well-established ones.

\footnotetext{
${ }^{1}$ After William of Occam (derived from the name of the village Ockham in Surrey, England), a 14th century logician.
} 
The scope of this paper is restricted to nonexpansive unsaturated soils. Section 2 gives a brief historical review of Terzaghi's effective stress principle and attempts by Bishop and many others to modify or extend it to make it applicable to unsaturated soils. Experimental and theoretical developments, with comments on their validity and relevance, are given in Section 3. In that section, it is demonstrated that a large number of experimental tests on soils under constant suction could be satisfactorily interpreted without invoking any new theories, postulates or assumptions. Section 4 provides a discussion on microstructure of saturation while Section 5 describes a rational alternative approach to modeling the behaviour of unsaturated soils for different types of microstructure of saturation. Here, it is shown that the only new parameter required for the description of mechanical behaviour is a measure of 'average pore size', which is related to other scalar descriptors already established in classical soil mechanics. Section 6 gives the conclusions and directions for future research.

\section{THE ENIGMA OF EFFECTIVE STRESS}

The basic concept of 'effective' stress principle for a porous medium saturated by water at the excess of pore pressure $p_{w}$, i.e.,

$$
\sigma_{i j}=\sigma_{i j}^{\prime}+p_{w} \delta_{i j}
$$

was originally proposed by Terzaghi [6]. It is the corner stone of modern soil mechanics and is explained and discussed in undergraduate text books. It is accepted that the mechanical response (deformation and failure) of soil is governed by effective stress and not the 'total' stress. Equation (1) is essentially a statement of equilibrium for a fully saturated granular material where the contact areas between grains are infinitesimal. In engineering practice total stress failure analyses are sometimes used but engineers do understand their limitations. The validity of effective stress principle for low porosity rocks, concrete and other 'rock-like' materials, in which grains are cemented, has also been extensively discussed in literature and revisions have been proposed ([7]-[10]).

Bishop and Blight [11] proposed a modification to equation (1) to be valid for unsaturated soils at various degrees of saturation. Their proposal is empirical and is based on experiments conducted on sands and silts. The equation reads

$$
\sigma_{i j}=\sigma_{i j}^{\prime}+\left(\chi p_{w}+(1-\chi) p_{a}\right) \delta_{i j}
$$

where $p_{a}$ is the excess air pressure, while the parameter $\chi$ is considered to be related to the degree of saturation $S_{r}$. The equation has been so organised that it reduces to equation (1) for $S_{r}=1$ (i.e., fully saturated soil). Numerous papers on determining parameter $\chi$ in Bishop's empirical equation are still being published. They include the work of Masin [12], Lu et al. [13], Khallili and Khabbaz [14], Baker and Frydman [15] amongst many others.

The behaviour of unsaturated soils seems to have almost disappeared as a topic of research in the period between 1970-1985. During this period, perhaps due to availability of fast computers and numerical methods such as the Finite Element Method, the research focus was on constitutive models of dry or fully saturated geomaterials. Recently, the topic of stress decomposition in partially saturated soils has been revived as indicated by a Euromech Colloquium 539 on 'Effective Stress Principle' organised in 2012 as well as publication of Special Issues of Journals like Computer and Geotechnics [16] and Vadose Zone Journal [17].

\section{EXPERIMENTAL AND THEORETICAL DEVELOPMENTS IN THE MECHANICS OF UNSATURATED SOILS - SOME BRIEF COMMENTS}

\subsection{EXPERIMENTAL DEVELOPMENTS}

It is important to note that geotechnical engineers got involved in research in the area of unsaturated soils when many concepts and experimental techniques had already been established by soil scientists (e.g., [18]-[20]). For example, the axis translation technique to avoid dealing with negative pore pressure was used by Bishop as early as 1950. Also, the fact that imbibition (progressive flooding) and drainage (progressive reduction in water content) induces a hysteresis loop leading to an irreducible degree of saturation was well known to engineers in petroleum industry since early 1960's.

Some significant developments on the experimental side have been reported. These include, among others, methods of using osmotic pressure and controlled vapour phase to test soils at suctions up to $2 \mathrm{MPa}$ and $100 \mathrm{MPa}$, respectively. However, relevance of such tests for geotechnical projects is questioned by some researchers [15]. In these proj- 
ects, the air pressure is atmospheric whilst water pressure cannot drop below $-100 \mathrm{kPa}$ to $-150 \mathrm{kPa}$ depending on the purity of water as cavitation will take place and water cannot exist in liquid phase.

Another growth area of experimental research has been determination of Soil Water Retention (or Characteristic) Curves (SWRC or SWCC) for various types of soils. A number of analytical expressions have also been developed to fit experimentally obtained SWRC. They are based on the belief that 'suction' alone could not explain the experimentally observed behaviour of unsaturated soils. Thus, the empirical equation developed in agricultural engineering by van Genuchien [21] has been modified [22]-[24] by introducing a number of constants having no physical meaning, with the intention that such formulations can be coupled with a constitutive model for unsaturated soil. It is worth noting that an experimentally determined SWRC can be used to determine a corresponding pore-size distribution curve. From this, parameters such as 'average pore size' can be determined. The latter parameter has a clear physical meaning and can be directly incorporated in the theoretical formulation, as discussed later in Section 5.

\subsubsection{INTERPRETATION OF TEST RESULTS}

Mechanical response of unsaturated soils has usually been determined from a series of 'constant suction' tests. These tests, in which the difference in pressures of water and air phases is maintained as constant, are in fact 'drained' tests. They simply represent the response of the soil skeleton subjected to an additional effective confining pressure which should be considered in interpretation of results.

In a saturated soil, free flow of pore fluid from the soil sample leads to drained conditions and no excess pore pressure can be generated. Thus pore fluid plays no role in mechanical behaviour. When an unsaturated soil sample is subjected to increasing suction, migration of pore water within the sample takes place internally but excess pore pressure cannot be generated until the degree of saturation approaches a high value of 0.9 or so. A large number of constant suction tests have another constraint. They are, by and large, 'constant water content' tests. There may be a small quantity of flow from the boundaries of the sample but this flow can be assumed as negligible.

To prove this point, we consider the results of different tests conducted by three researchers; i.e., Josa et al. [26], Zakaria [27] and Shivkumar [28].

\section{Josa et al. [26]}

Table 1 provides the results of a series of triaxial compression tests on partially saturated sandy/silty soil under constant suction pressure. The first four columns in Table 1 show test identification number, confining pressure $(p)$, suction pressure $(s)$ and strength, respectively, for the 13 tests reported. It is noted that the test number 5 was conducted with no suction pressure and is therefore a standard triaxial test. Thus, the conditions at failure for this test allow to estimate the effective friction angle. Treating now the suction pressure as an additional effective confining pressure, the strength $q_{f}$ can be computed and the corresponding values are shown in column 5 . The predicted values of strength are in agreement with those measured within the margins of experimental error. It is no surprise, therefore, that doubts have been expressed [29] whether the degree of saturation affects the response.

\begin{tabular}{|c|c|c|c|c|c|}
\hline $\begin{array}{c}\text { Test } \\
\#\end{array}$ & $\begin{array}{c}p \\
(\mathrm{kPa})\end{array}$ & $\begin{array}{c}\mathrm{s} \\
(\mathrm{kPa})\end{array}$ & $\begin{array}{c}q_{f} \text { measured } \\
(\mathrm{kPa})\end{array}$ & $\begin{array}{c}q_{f} \text { calculated } \\
(\mathrm{kPa})\end{array}$ & $\begin{array}{c}\% \\
\text { Error }\end{array}$ \\
\hline 1 & 142 & 9.7 & 132 & 131 & 0 \\
\hline 2 & 142 & 14.2 & 149 & 135 & 9 \\
\hline 3 & 137 & 95 & 228 & 200 & 12 \\
\hline 4 & 280 & 16 & 241 & 255 & 6 \\
\hline 5 & 340 & 0 & 293 & 293 & 0 \\
\hline 6 & 475 & 10 & $370 *$ & 417 & 13 \\
\hline 7 & 390 & 95 & 377 & 418 & 10 \\
\hline 8 & 325 & 91 & 384 & 360 & 6 \\
\hline 9 & 544 & 40 & 500 & 503 & 1 \\
\hline 10 & 557 & 41 & 500 & 515 & 3 \\
\hline 11 & 558 & 16 & 508 & 495 & 3 \\
\hline 12 & 590 & 97 & 567 & 590 & 4 \\
\hline 13 & 540 & 95 & 567 & 549 & 3 \\
\hline
\end{tabular}

* This value appears to be too low since even without suction the strength should have been higher than $410 \mathrm{kPa}$ in view of test \# 5.

\section{Zakaria [27]}

In another series of experiments, either axial or hydrostatic compression tests at constant suction were conducted on compacted Speswhite kaolin, by Zakaria [27]. Here, evolution of $S_{r}$ as a function of continuing deformation was recorded. As mentioned earlier, these tests are such that no significant amount of water flows out of the samples. In other words, in these tests water content in the sample remains constant. In order to interpret results of these tests, wellknown phase relationship is invoked

$$
S_{r} e=w G_{s}
$$


where $e$ is the void ratio, $w$ is the water content and $G_{s}$ is the specific gravity of solids. Noting that during these tests water content is constant, differentiation of equation (3) leads to

$$
\begin{gathered}
d S_{r}=-S_{r} \frac{d e}{e} \\
d e=-(1+e) d \varepsilon_{V} \Rightarrow d S_{r}=S_{r} \frac{(1+e)}{e} d \varepsilon_{V}
\end{gathered}
$$

where $d \varepsilon_{V}$ is the volumetric strain increment which can be computed from the constitutive relation of soil skeleton. Adopting, for example, the well-known Critical State Model, yields

$$
\begin{gathered}
d \varepsilon_{V}=d \varepsilon_{v}^{e}+d \varepsilon_{v}^{p} \\
=\frac{\kappa}{1+e_{0}} \frac{d p^{\prime}}{p^{\prime}} \\
+\frac{\lambda-\kappa}{p^{\prime}\left(1+e_{0}\right)\left(M^{2}+\eta^{2}\right)}\left[\left(M^{2}-\eta^{2}\right) d p^{\prime}+2 \eta d q\right]
\end{gathered}
$$

where $\lambda, \kappa$ are the compression and swelling indexes, $M$ is the stress ratio $\eta=p^{\prime} / q$ at failure and $e_{0}$ is the initial void ratio. Equation (5) can be substituted in equation (4) to define the evolution of $S_{r}$ during the deformation process. Note that under hydrostatic compression, the latter simplifies to

$$
d S_{r}=S_{r} \frac{\lambda}{e} \frac{d p^{\prime}}{p^{\prime}} .
$$

In the expression above, the initial effective confining pressure $p^{\prime}$ should include the value of suction pressure.

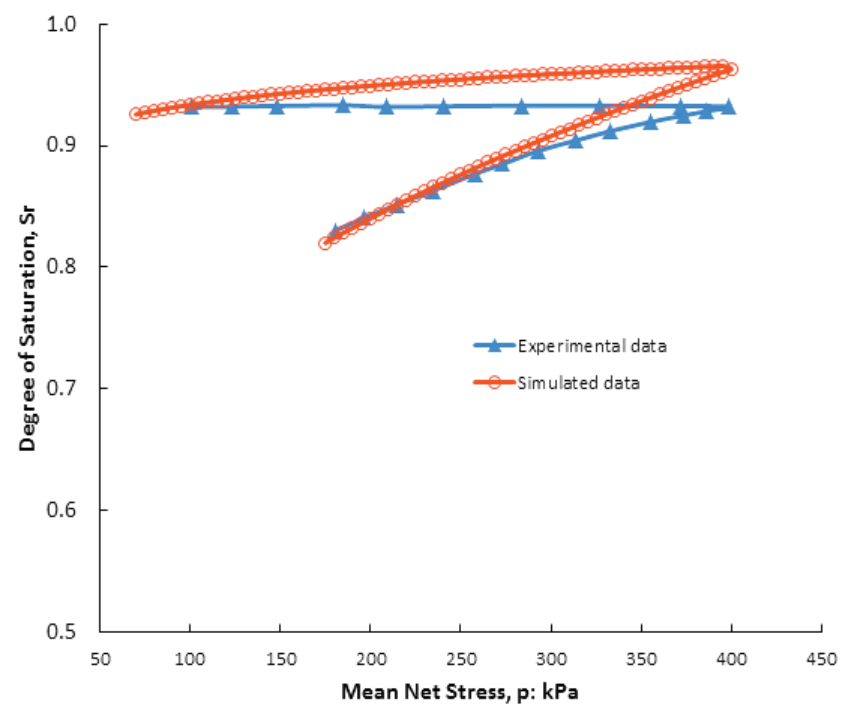

Fig. 1. Experimental data and numerical simulation of isotropic compression test at constant suction
Assuming that Speswhite kaolin will demonstrate typical response according to the Critical State Model, numerical simulation of physical tests was carried out. The following parameters were assumed: $\lambda=0.25$, $\kappa=0.03, e_{0}=1.4$, while the initial degree of saturation was taken as 0.82 . Results of experiment and numerical simulations are provided in Fig. 1. It can be seen that the predictions are fairly consistent with the results of the test.

\section{Sivakumar [28]}

The above reference provides the results of a series of triaxial and isotropic compression tests conducted on Speswhite kaolin at different initial suction pressures. In Fig. 2 results of a triaxial test conducted at a constant suction of $200 \mathrm{kPa}$ and initial value of $S_{r}=0.75$ are shown. Here, evolving degree of saturation is plotted against deviatoric stress. Numerical simulation of the test, using the same material parameters for Speswhite clay as adopted for simulation of Zakaria's test, is shown in Fig. 2. Again, the results of experiment and numerical simulation are seen to match quite well.

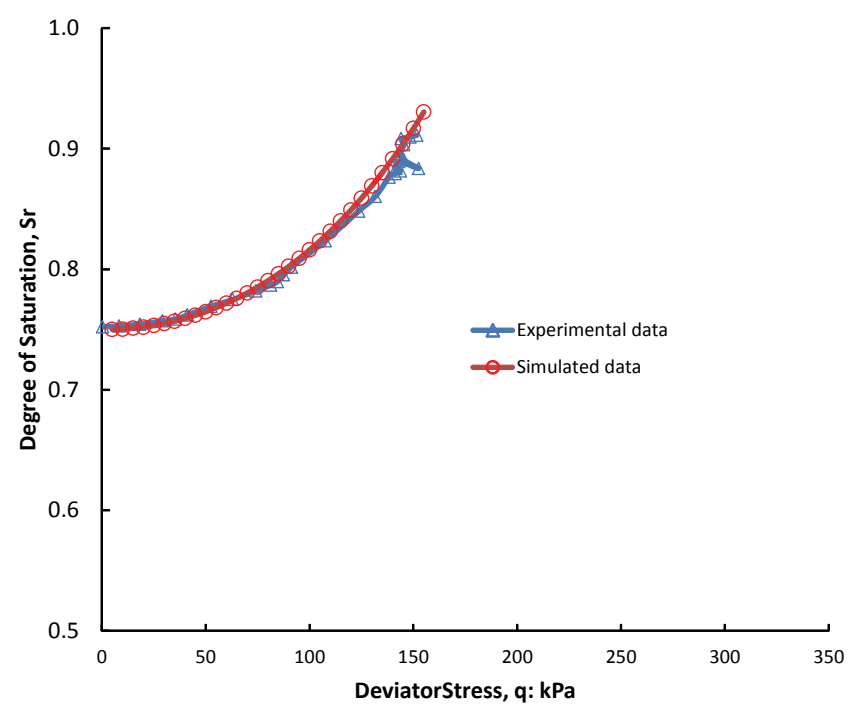

Fig. 2. Degree of saturation against deviatoric stress in triaxial test at constant suction - experimental results (Shivkumar [28]) and numerical simulation

Figure 3 shows results of isotropic compression tests at different suction pressures of $100 \mathrm{kPa}$, $200 \mathrm{kPa}$ and $300 \mathrm{kPa}$ at initial values of $S_{r}$ equal to $0.67,0.62$ and 0.58 , respectively. Here, specific volume, $v=1+e$, is plotted against the evolution of degree of saturation. Once again, numerical simulation results are consistent with experimental measurements. 


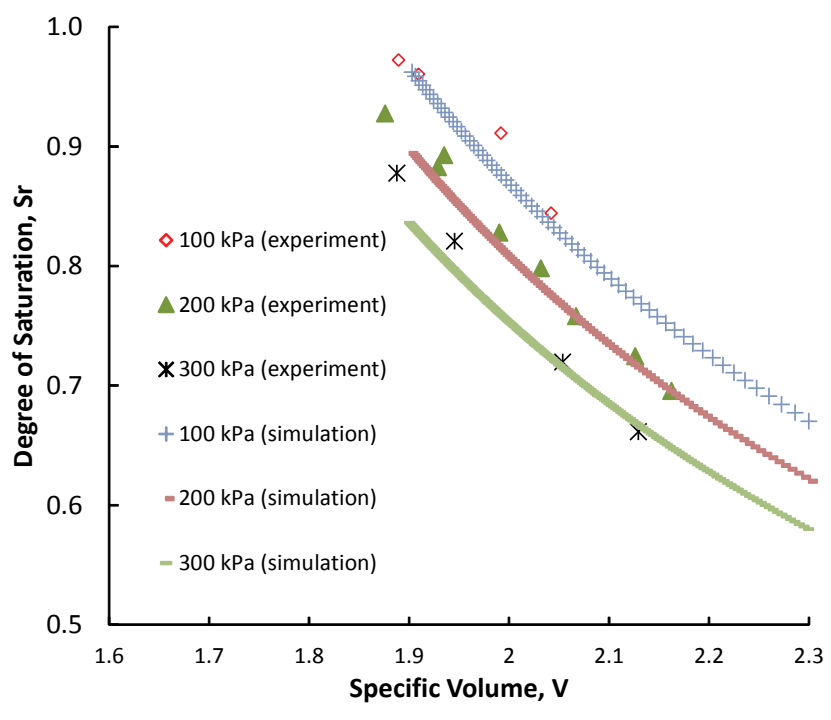

Fig. 3. Degree of saturation against specific volume in triaxial tests at constant suction - experimental results

(Shivkumar [28]) and numerical simulation

It is clear from the above examples that no additional parameters or hypotheses are required for interpretation of results of constant suction tests. In addition, specification of an independent SWRC is not only unnecessary but may, in fact, be in conflict with the basic phase relations of soils. In recent years, many more test results of isotropic compression as well as compaction under $K_{0}$ conditions followed by application of constant suction and constant water content have been reported; e.g., Tarantino and De Col [30 ], Tarantino and Tombolato [31]. Additional independent relationships between degree of saturation and suction proposed by these authors may not be necessary.

\subsection{THEORETICAL DEVELOPMENTS}

As pointed out in Section 1, there has been a large number of papers published on experimental, numerical and theoretical aspects of the mechanics of unsaturated soils. It is not possible to comment on them individually. Here, some brief comments on various approaches for developing hydro-mechanical models for unsaturated soils are provided. It is assumed that all models are intended for the purpose of solving boundary value problems of interest to engineers. Numerical implementation has indeed been reported, however, only few practical problems seem to have been solved [32].

The Critical State framework of strain hardening plasticity was adopted by Alonso et al. [33] who developed a constitutive model for unsaturated soils using matrix suction $(s)$ as an independent state parameter. Their model, popularly known as BBM (Basic Barcelona Model), prompted vigorous research activity leading to many more models being enhanced to account for variation of $s$ with the degree of saturation $S_{r}$. Noting that a hysteretic loop is formed in $S_{r}$ versus $s$ curve when soil is wetted (increasing $S_{r}$ ) and then dried (decreasing $S_{r}$ ), many models were proposed to account for this aspect (e.g., [34]-[36]). A common feature of models described in references [34]-[36] is that $S_{r}$ versus $s$ relation is assumed to be independent of volumetric strains. This assumption is restrictive and it has led some investigators (e.g., [23], [24]) to include an arbitrary dependence of $S_{r}$ versus $s$ relationship on $e$ (void ratio). Unfortunately this step is unwarranted as has been shown in Section 3.1 and conflicts with basic phase relations of soil mechanics.

Another subject, which has interested experimentalists as well as numerical modellers in the past two decades, is the behaviour of unsaturated 'expansive' soils. Construction of buildings and structures in such soils, without a proper understanding of their behaviour and appropriate measures, causes damage and losses running in billions of dollars. These soils and rocks display volume change triggered by change in water content at low degrees of saturation. The origin of these 'autogenous' strains is the chemical reaction in the clay minerals at the particle contacts which causes swelling of 'clayey gel' on wetting and shrinkage on drying. These strains are not caused by mechanical stress and should be separated from those caused by suction. The framework of BBM was extended by Gens and Alonso [37] to include problematic soils. A large number 'soil specific' constitutive formulations for unsaturated soils have also been developed (e.g., ([38]-[40]). However, it is clear that a rational model for any 'expansive' soil should be such that it reduces to a standard soil model in absence of saturation induced volumetric strains. This can, for example, be achieved by following the framework of chemo-plasticity ([41]-[43]) as shown in Section 5(i).

The phenomenon of 'collapse' on wetting of non-expansive unsaturated soils was noted in isotropic, one-dimensional as well as triaxial compression [44]-[46]. This behaviour cannot be properly explained by constitutive models such as BBM [33], therefore new extended models were proposed [47]-[49]. However, it was shown by the authors of this paper in 1995 [48], that the phenomenon of collapse could be explained if an appropriate 'deviatoric' or 'combined volumetric-deviatoric' hardening 
model is adopted within the framework proposed in Section 5 (ii). It should be pointed out again that the hydro-mechanical properties of unsaturated soils are strongly dependent on the microstructure of saturation and its evolution. This is further discussed in Section 4 below.

\section{MICROSTRUCTURE OF SATURATION}

In general, four different types of microstructure can be distinguished in partially saturated soils ([51]-[53]), as illustrated in Fig. 4. These are stable forms and can be encountered in-situ in geotechnical structures like slopes and embankments. Within the range of irreducible saturation the air phase is continuous while the water phase is discontinuous, i.e., the water adheres to inter-particle contacts (saturation type A). In this case the properties of water in the vicinity of minerals are different from those of free water and cannot, in fact, be quantified. As a result, the control and measurement of suction pressures is not possible (cf. [15]). At higher degrees of saturation $\left(S_{r}>0.2\right.$ approx.) the water phase also becomes continuous (type B). Then, at much higher degrees of saturation $\left(S_{r}>0.9\right)$ the air phase may become discontinuous, i.e. air can be in the form of tiny bubbles embedded in water (saturation type $C$ ). It is noted that the transition of microstructure from type (A) to (B) to $(\mathrm{C})$ is not continuous as abrupt changes take place.

There is yet another form of partial saturation referred to as 'gassy soil'. In this case, the gas phase is discontinuous in the form of discrete bubbles that are entrapped in a fully saturated matrix (type D). Such a microstructure is typically formed when the gas (produced by decomposition of organic matter) pushes against the skeleton creating voids of the size much larger than the particle size.

There are two more types of microstructures which are likely to arise during 'constant suction' tests. These are shown in Fig 5. In the wetting phase, water percolates through the channels formed by pores of small sizes first and then moves progressively into the larger ones, Fig. 5(a). On the other hand, in the drying phase, air intrudes larger pores and these are emptied first, Fig. 5(b). Here, progressively smaller diameter channels are formed as air pressure is increased. There is indirect evidence that the above microstructures do arise particularly in Pressure Plate Tests used for determining SWRC. It has been recently shown [25] that pore size distribution obtained on the assumption of microstructure in Fig. 5(b) matches fairly well with that obtained from Mercury Intrusion Porosimetry. It is evident that during the wetting as well as drying phases, the sample becomes heterogeneous and in both cases isolated clumps of soil (dry or wet) are formed within the specimen. Thus, the evolution of microstructure in 'constant suction' tests represents, in fact, an initial boundary value problem.

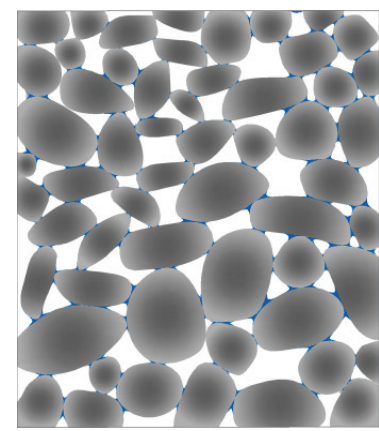

(A)

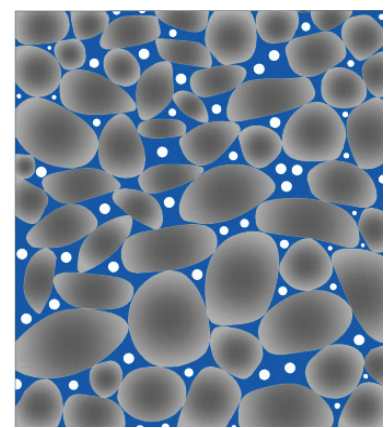

(C)

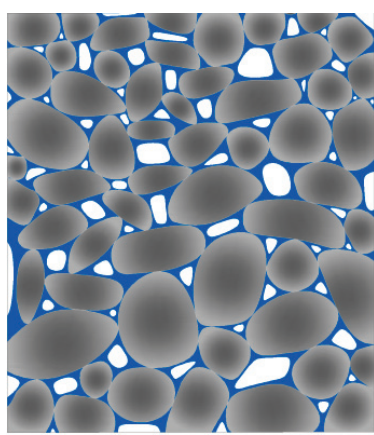

(B)

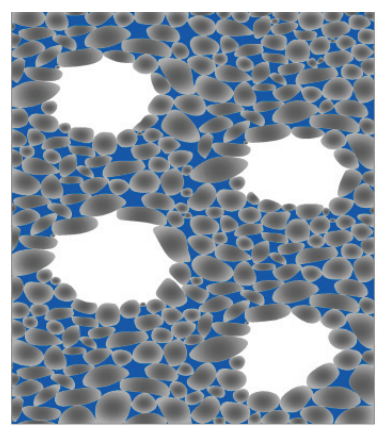

(D)
Fig. 4. Schematic representation of micro-structure of saturation:

(A) Air phase continuous but water phase discontinuous;

(B) Water and air phases both continuous; (C) High degree of saturation - water phase continuous but air phase discontinuous; (D) Air phase discontinuous - gassy soils

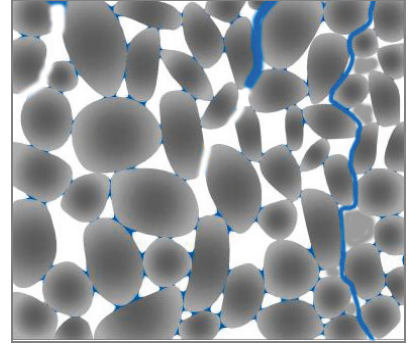

(a)

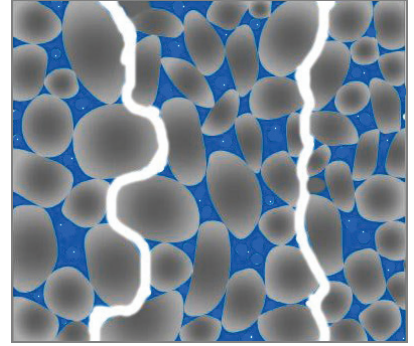

(b)
Fig. 5. Schematic representation of possible micro-structure of saturation during constant suction tests: (a) wetting phase (b) drying phase

It is noted that the approaches incorporating suction as a state variable are phenomenological in nature and do not refer to any specific type of microstructure 
of saturation. Their use is rather questionable for soil type A as suction pressure is not a mechanical variable but results from a difference in chemical potentials. As such, it cannot be controlled/measured [15]. As mentioned earlier, for microstructures types B, C and D the liquid (water) phase is continuous and has known mechanical properties, i.e., low compressibility and virtually no viscosity. In this case, for each specific geometric arrangement of the microstructure of saturation, the mechanical properties can be defined in terms of properties of the skeleton, air and the free water. In the following section a formulation for describing hydromechanical response of unsaturated soils based on the specific microstructure of saturation is presented. It is demonstrated that the crucial parameter required to be introduced for unsaturated porous media is a statistical measure of an 'average pore size'. This measure is directly related to 'particle size distribution' or 'gradation curve' of soils, which are both well integrated in the study of classical soil mechanics.

It is important to point out that flow of fluids viz. air or water corresponding to any microstructure of saturation can take place when and only when excess pore water or air pressure are generated or there is a hydraulic gradient to establish steady state flow. In a constant suction test at low degrees of saturation, a continuous flow out of the sample is not possible.

\section{CONSTITUTIVE FORMULATIONS FOR UNSATURATED SOILS BASED ON MICROSTRUCTURE OF SATURATION}

\section{(i) Water phase discontinuous (microstructure type A)}

As mentioned in the previous section, in the range of saturation close to its irreducible value, the water phase is discontinuous and the soil microstructure is of the type A. In this case, the specification of properties, particularly in clayey soils, is difficult as the problem involves complex physical-chemical interactions and the properties of water in the vicinity of minerals cannot be quantified. Thus, the problem cannot be approached as purely mechanical one. In view of these difficulties, the approach advocated here for the type A microstructure is based on the phenomenological framework of chemo-plasticity [41] which, in authors' opinion, is preferred to the classical notions of unsaturated soil mechanics. Within this ap- proach, the progress in chemo-mechanical interaction is monitored by a scalar parameter $\zeta$, which may be interpreted as the change in the initial suction pressure $u_{s}^{0}$, at the irreducible wetting fluid saturation, within a representative volume; i.e., $\zeta \propto\left(u_{s}^{0}-u_{s}\right) / u_{s}^{0}$, so that $\zeta \subset[0,1]$. The evolution law can be taken in a simple linear form

$$
\frac{\partial \zeta}{\partial t^{\prime}}=B(1-\zeta) ; \quad \partial t^{\prime}=\mathrm{g} d t
$$

where $g \subset[0,1]$ depends on the chemical composition of the clay minerals and water, and $B$ is a material constant. In the elastic range, the constitutive relation takes the form

$$
\varepsilon_{i j}^{e}=C_{i j k l}^{e} \sigma_{k l}+\varepsilon \zeta \delta_{i j} .
$$

Here, $C_{i j k l}^{e}$ is the elastic compliance operator and the last term represents the volumetric strain due to wetting, with $\varepsilon$ being the maximum expansion/contraction in the stress-free state. Note that the differential form of equation (8) may be expressed as

$$
\dot{\varepsilon}_{i j}^{e}=C_{i j k l}^{e} \dot{\sigma}_{k l}+\left(\partial_{\zeta} C_{i j k l}^{e} \sigma_{k l}+\varepsilon \delta_{i j}\right) \dot{\zeta} .
$$

In order to specify the plastic strain rates, the functional form of the yield criterion $f=0$ is assumed to be affected by the chemical interaction, i.e.,

$$
f=f\left(\sigma_{i j}, \kappa, \zeta\right)=0 ; \quad \kappa=\kappa\left(\varepsilon_{i j}^{p}\right) ; \quad \dot{\varepsilon}_{i j}^{p}=\dot{\lambda} \frac{\partial \psi}{\partial \sigma_{i j}} .
$$

where $\kappa=\kappa\left(\varepsilon_{i j}^{p}\right)$ is the hardening parameter and $\psi=\psi\left(\sigma_{i j}, \zeta\right)$ is the plastic potential function. Employing now the consistency condition, the plastic multiplier $\dot{\lambda}$ can be defined as

$$
\begin{gathered}
\dot{f}=0 \Rightarrow \dot{\lambda}=\frac{1}{H}\left(\frac{\partial f}{\partial \sigma_{i j}} \dot{\sigma}_{i j}+\frac{\partial f}{\partial \zeta} \dot{\zeta}\right) ; \\
H=-\frac{\partial f}{\partial \kappa} \frac{\partial \kappa}{\partial \varepsilon_{i j}^{p}} \frac{\partial \psi}{\partial \sigma_{i j}} .
\end{gathered}
$$

Thus, invoking the additivity postulate and using the equations (9)-(11), the constitutive relation may be expressed as

$$
\begin{gathered}
\dot{\varepsilon}_{i j}=C_{i j k l} \dot{\sigma}_{k l}+b_{i j} \dot{\zeta} ; \\
b_{i j}=\partial_{\zeta} C_{i j k l}^{e} \sigma_{k l}+\frac{1}{H} \frac{\partial f}{\partial \zeta} \frac{\partial \psi}{\partial \sigma_{i j}}+\varepsilon \delta_{i j} \\
C_{i j k l}=C_{i j k l}^{e}+\frac{1}{H} \frac{\partial \psi}{\partial \sigma_{i j}} \frac{\partial f}{\partial \sigma_{k l}} .
\end{gathered}
$$


It is noted that within this approach, an increase in water content due to wetting is said to trigger a reduction in the inter-particle bonding and the corresponding degradation of strength and deformation properties at the macroscale (viz. dependence of $f$ and $C_{i j k l}^{e}$ on $\zeta$ ). At the stage when the water phase becomes continuous, the behaviour can be defined in mechanical terms alone, i.e. using the framework discussed below.

\section{(ii) Water and air phases continuous (microstructure type B)}

Consider now the most common scenario which involves a microstructure of saturation such that both air and water phases remain continuous. The mathematical formulation for this case was discussed by the authors at a Symposium in 1995 [50]. Essential parts of this formulation are presented here for continuity and clarity as well as for wider dissemination amongst the research community.

The average macroscopic stress, $\sigma_{i j}$, within a representative volume $V$, may be defined as

$$
\sigma_{i j}=\frac{1}{V}\left(\int_{V_{s}} \bar{\sigma}_{i j}^{s} d V_{s}+\int_{V_{s}} \bar{p} \delta_{i j} d V_{V}\right)
$$

where $\bar{\sigma}_{i j}^{s}$ is the stress field in the skeleton and $\bar{p}$ is the pressure field in the voids measured above a threshold value (atmospheric pressure). The integrals appearing in equation (13) are proportional to the respective volume average of both fields, i.e.

$$
\sigma_{i j}^{s}=\frac{1}{V_{S}} \int_{V_{S}} \bar{\sigma}_{i j}^{s} d V_{S} ; \quad p=\frac{1}{V_{V}} \int_{V_{V}} \bar{p} d V_{V}
$$

where $\sigma_{i j}^{s}$ represents the average stress in the skeleton and $p$ is the average excess pressure in the voids. Substitution of equations (14) in equation (13) leads to

$$
\sigma_{i j}=(1-n) \sigma_{i j}^{s}+n p \delta_{i j}
$$

where $n=V_{V} / V$ is the porosity of the sample.

Consider now the interconnected voids as a freebody. The average pressure, $p$, may be defined as

$$
p=\frac{1}{V}\left(\int_{V_{W}} \bar{p}_{w} d V_{w}+\int_{V_{a}} \bar{p}_{a} d V_{a}-\int_{S_{m}} T d S_{m}\right)
$$

where $\bar{p}_{w}$ and $\bar{p}_{a}$ represent the excess pressure in the water (occupying volume $V_{w}$ ) and air (of volume $V_{a}$ ), respectively. Moreover, $T$ represents the surface ten- sion force (per unit length of the air-water meniscus) and $S_{m}$ is the surface area of air-water menisci.

Denoting by $p_{w}$ and $p_{a}$ the volume averages of $\bar{p}_{w}$ and $\bar{p}_{a}$, equation (16) may be expressed as

$$
p=S_{r} p_{w}+\left(1-S_{r}\right) p_{a}-\frac{T S_{m}}{V_{V}} .
$$

In the microstructure type $B$ the grains are considered to be in a direct contact with water, therefore, $p=p_{w}$, so that equation (17) reduces to

$$
p_{a}-p_{w}=\frac{T S_{m}}{V_{V}\left(1-S_{r}\right)} .
$$

The value of $S_{m}$ may be assumed as being proportional to the total surface area of solids. The latter is a measurable quantity and various experimental techniques for its determination are available (e.g., equilibrium ethylene glycol method, the use of laser diffraction particle size analyser; cf. [54], [55]). Given the approximation $S_{m}=\xi S_{S}$, the suction pressure may be defined as

$$
p_{a}-p_{w}=\frac{\xi T}{\rho_{V}\left(1-S_{r}\right)}=\beta ; \quad \rho_{V}=\frac{V_{V}}{S_{S}}
$$

where $\xi$ is a constant $(\xi \rightarrow 1$ when water adheres to grain boundaries) and $\rho_{V}$ represents the average pore size defined in a way similar to the concept of hydraulic radius.

Consider now the constitutive relation governing the behaviour of the soil skeleton. Assume that the response of a dry material can be described by an incremental relation

$$
\dot{\sigma}_{i j}=\left\{(1-n) \sigma_{i j}^{s}\right\}^{\bullet}=D_{i j k l} \dot{\varepsilon}_{k l} .
$$

For type B microstructure, the grains are considered to be surrounded by water at an excess pressure of $p_{w}$. In this case, the response of the skeleton alone must be consistent with that given by equation (20), i.e.,

$$
\left\{(1-n)\left(\sigma_{i j}^{s}-p_{w} \delta_{i j}\right)\right\}^{\bullet}=\dot{\sigma}_{i j}^{\prime}=D_{i j k l} \dot{\varepsilon}_{k l}
$$

where $\sigma_{i j}^{\prime}$ is referred to as the effective stress. It should be noted that, according to equation (21)

$$
\sigma_{i j}^{\prime}=(1-n) \sigma_{i j}^{s}-(1-n) p_{w} \delta_{i j} .
$$

The above definition, combined with equation (3), leads to classical Terzaghi's decomposition (1)

$$
\sigma_{i j}=\sigma_{i j}^{\prime}+p_{w} \delta_{i j} .
$$


It is important, at this point, to comment on the initial conditions within the specimen. Neglecting the stress due to self-weight and assuming that the air pressure is initially at the atmospheric level, i.e., $\sigma_{i j}=0$ and $p_{a}=0$, leads to

$$
\sigma_{i j}^{\prime}=-p_{w} \delta_{i j}=\beta \delta_{i j} .
$$

Taking some typical values of $T=65^{*} 10^{-6} \mathrm{kN} / \mathrm{m}$, $S_{r}=0.4$, and assuming that the material considered is a clay with $\rho_{V} \approx 0.0002 \mathrm{~mm}$, yields $1 / 3 \sigma_{i i}^{\prime}=-p_{w}$ $\approx 540 \mathrm{kPa}$ as the initial condition. On the other hand, in cohesionless granular materials, like sand, the value of $\rho_{V}$ is several orders of magnitude larger than that corresponding to clay. Taking, for example, $\rho_{V} \approx 0.2 \mathrm{~mm}$ yields $1 / 3 \sigma_{i i}^{\prime}=-p_{w} \approx 0.5 \mathrm{kPa}$. Thus, in fine grained soils, the initial conditions will have a profound effect on the deformation characteristics. At the same time, in materials with larger average pore size, the response will be only marginally affected by the presence of the liquid phase.

Consider now the response under undrained conditions. Express first the volumetric strain rate $\dot{\varepsilon}_{i i}=-\dot{V}_{V} V$ (where $\dot{V}_{V}=\dot{V}_{a}+\dot{V}_{w}$ ) in terms of respective averages $\dot{\varepsilon}_{i i}^{a}=-\dot{V}_{a} / V_{a}$ and $\dot{\varepsilon}_{i i}^{w w}=-\dot{V}_{w} / V_{w}$ as

$$
\dot{\varepsilon}_{i i}=n\left\{\left(1-S_{r}\right) \dot{\varepsilon}_{i i}^{a}+S_{r} \dot{\varepsilon}_{i i}^{w}\right\} .
$$

The stress-strain relations for the constituent materials take the form

$$
\dot{\sigma}_{i j}^{\prime}=D_{i j k l} \dot{\varepsilon}_{k l} ; \quad \dot{p}_{w}=K_{f} \dot{\varepsilon}_{i i}^{w} ; \quad \dot{p}_{a}=K_{a} \dot{\varepsilon}_{i i}^{a}
$$

where $K_{f}$ is the bulk modulus of water and $K_{a}=p_{a}+p_{0}$, with $p_{a}$ representing the atmospheric pressure. Differentiating equation (19) with respect to time yields

$$
\dot{p}_{a}-\dot{p}_{w}=\left(\frac{\xi T S_{S}}{V_{V}} \frac{V_{V}}{V_{a}}\right)=\xi T S_{S}\left(\frac{1}{V_{a}}\right)=\beta \dot{\varepsilon}_{i i}^{a} .
$$

At this point, it is convenient to assume that the volumetric strain rates in both constituents can be uniquely derived from $\dot{\varepsilon}_{i i}$, i.e.,

$$
\dot{\varepsilon}_{i i}^{a}=B_{a} \dot{\varepsilon}_{i i} ; \quad \dot{\varepsilon}_{i i}^{w}=B_{w} \dot{\varepsilon}_{i i} .
$$

Substituting these relations in equations (26) and (27), yields

$$
\dot{p}_{a}-\dot{p}_{w}=\left(K_{a} B_{a}-K_{f} B_{w}\right) \dot{\varepsilon}_{i i}=\beta B_{a} \dot{\varepsilon}_{i i} .
$$

At the same time, equations (25) and (28) result in

$$
\frac{1}{n}=\left(1-S_{r}\right) B_{a}+S_{r} B_{w} .
$$

Solving now the set of simultaneous equations (29) and (30), yields

$$
B_{w}=\frac{1}{n\left\{S_{r}+\left(1-S_{r}\right) \frac{K_{f}}{K_{a}-\beta}\right\}} ; \quad B_{a}=\frac{K_{f}}{K_{a}-\beta} B_{w} .
$$

Finally, differentiating equation (23) with respect to time and utilizing equations (26) and (28), the following constitutive relation is obtained

$$
\dot{\sigma}_{i j}=\left(D_{i j k l}+K_{f} B_{w} \delta_{i j} \delta_{k l}\right) \dot{\varepsilon}_{k l} .
$$

The above relation governs the undrained response of partially saturated soils at low degrees of saturation. It should be noted that in coarse grained soils, the influence of $\beta$ is marginal, so that the terms in $K_{f} B_{w}$ are of the order of atmospheric pressure and remain negligible compared to individual components of $D_{i j k l}$. Thus, $\dot{\sigma}_{i j} \approx D_{i j k l} \dot{\varepsilon}_{k l}$ and the undrained response is virtually the same as the drained one. In materials with small grain size, $p_{a} \ll\left|p_{w}\right|$ (as $p_{a}=0$ initially), so that $\beta \approx-p_{w}$ and consequently, $K_{f} B_{w} \rightarrow p_{w} /\left\{n\left(1-S_{r}\right)\right\}$. Thus the terms in $K_{f} B_{w}$, equation (20), become significant only at advanced stages of the deformation process and the mechanical response will differ only marginally from that corresponding to drained behaviour at the same initial conditions.

The framework presented above can be incorporated in any constitutive model for soil skeleton. The formulation simply extends the applicability of the latter to unsaturated soil with any degree of saturation provided the microstructure of saturation is such that water as well as air phases are continuous. In this context, it is appropriate to offer some remarks on modelling of 'collapse' behaviour of compacted soils on wetting or 'soaking'. It is noted that many popular constitutive models for unsaturated soils like BBM are based on 'volumetric' hardening in the context of the theory of elasto-plasticity. Since the effective stress trajectory associated with soaking remains within the domain enclosed by the current yield surface, 'collapse' cannot be predicted. A more reasonable prediction may be obtained using a deviatoric hardening model, wherein the same stress trajectory results in an 'active' loading process. An example is provided below.

Consider a sample of an unsaturated soil, e.g., $S_{r}=0.4$, subjected to undrained triaxial compression at an initial confining pressure of $450 \mathrm{kPa}$. Assume that $T=65 \times 10^{-6} \mathrm{kN} / \mathrm{m}, \xi=1, \rho_{v}=3.8 \times 10^{-4} \mathrm{~mm}$. Since the air phase is considered here to be interconnected, the initial air pressure is zero, $p_{a}=0$, which leads to 
$p_{w}=-\beta=-290 \mathrm{kPa}$. The numerical simulations were conducted for the following material parameters:

$$
\begin{gathered}
K=20 \mathrm{MPa}, G=15 \mathrm{MPa}, \\
\eta_{f}=M=1.5, \eta_{c}=1.45, \alpha=0.002,
\end{gathered}
$$

where $K$ and $G$ are bulk and shear moduli respectively, $\eta_{f}$ and $\eta_{c}$ are slopes of failure and zero dilatancy lines in $q-p^{\prime}$ space and $\alpha$ is material parameter appearing in hardening function [48]. Figure 6 shows $q$ versus $\varepsilon_{q}=2\left(\varepsilon_{1}-\varepsilon_{3}\right) / 3$ plot for initial value of $S_{r}=0.4$. It should be noted that under undrained conditions air and water both are not allowed to escape from the sample. Results corresponding to $S_{r}=1.0$ are also shown for drained as well as undrained conditions. It is evident that for unsaturated specimen the strength is the highest, while for the saturated sample the undrained strength is significantly lower than that under drained conditions. At certain levels of deviatoric stress, $q$, the unsaturated sample is now subjected to soaking. Ignoring the transient nature of the phenomenon and assuming that the microstructure of saturation remains uniform, an estimate of the collapse settlement can be made. For the considered process $\dot{\sigma}_{i j}=0$ which implies $\dot{\sigma}_{i j}=-\dot{p}_{w} \delta_{i j}$ with $p_{w}$ progressively increasing from prescribed initial value $\left(p_{w}<0\right)$ to $p_{w} \rightarrow 0$.

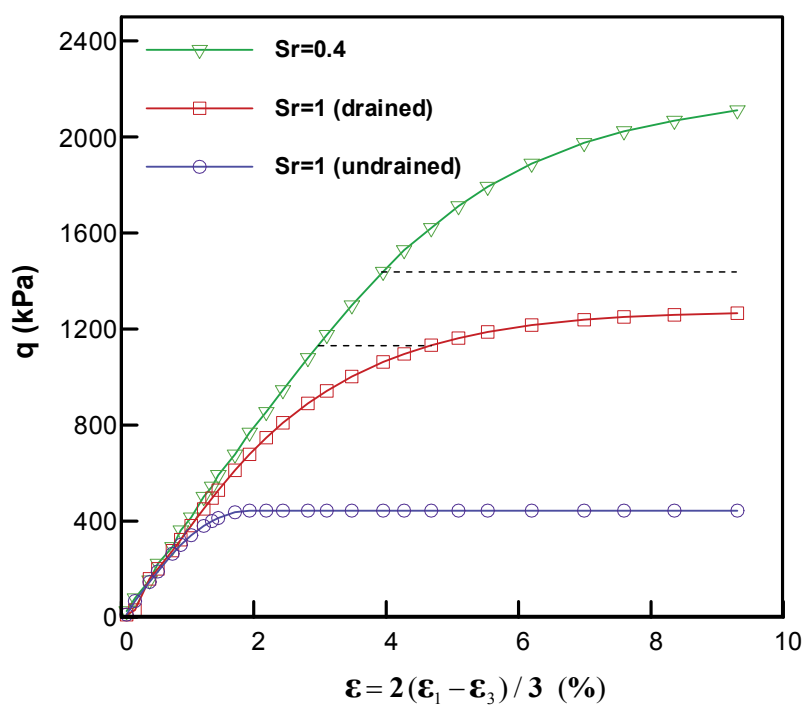

Fig. 6. Triaxial compression of unsaturated soil specimen at $S_{r}=0.4$. Results for $S_{r}=1.0$ (drained and undrained) are also shown

Figure 7 shows a graph of axial strain $\varepsilon_{1}$ against normalised suction $\left(1-s / s_{0}\right), s_{0}$ being initial suction, for $q=1150$ and $1400 \mathrm{kPa}$. If soaking takes place at $q=1150 \mathrm{kPa}$, vertical strain is seen to increase and a stationary state is attained whilst at a higher value of $q$, viz. $q=1400 \mathrm{kPa}$, a spontaneous collapse of the sample takes place and no stable equilibrium can be achieved.

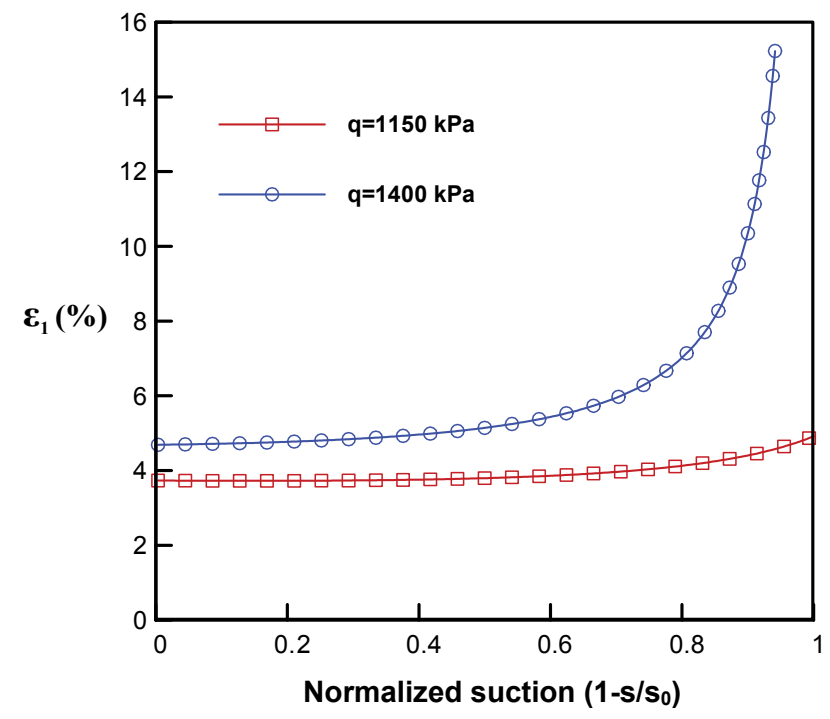

Fig. 7. Variation of vertical strain $\left(\varepsilon_{1}\right)$ against normalised suction $\left(1-s / s_{0}\right)$ due to soaking at $q=1150 \mathrm{kPa}$ and $1400 \mathrm{kPa}$

\section{(iii) Water phase continuous and air phase discontinuous (microstructure type C)}

It is instructive to compare the present formulation, equation (20), with that corresponding to high degrees of saturation at which the air phase becomes discontinuous (type $\mathrm{C}$ ). In this case, the difference in the mechanical behaviour is primarily the result of different initial conditions. If the soil is sufficiently desaturated for an interconnected air phase to exist, then the air is at atmospheric pressure and the liquid is below the atmospheric pressure. Thus, the initial effective stresses can be estimated based on equation (24). On the other hand, at high degrees of saturation, when the air is entrapped within the pore space, the liquid remains at atmospheric pressure whereas the air is at a pressure larger than atmospheric. Thus, according to decomposition (23), at $\sigma_{i j}=0$ there is $\dot{\sigma}_{i j}=0$. The mathematical formulation for describing the undrained response at high degrees of saturation was presented in the article by Pietruszczak and Pande [56]. The mathematical framework is, in general, similar to that presented above. The differences arise only from the approximation involving the suction pressure term, equation (19), which in the context of high degrees of saturation becomes

$$
p_{a}-p_{w}=\frac{2 T}{3 \rho_{V} \sqrt{1-S_{r}}}=\beta
$$


where $S_{r}$ is typically within the range $0.9 \leq S_{r}<1.0$. In general, the undrained response is quite sensitive to the degree of saturation and it may substantially differ from that corresponding to drained conditions.

It is noted that the formulation for soil containing large gas-filled voids embedded in a fully saturated matrix (microstructure type D) can be derived following a similar methodology in which the soil is perceived as a composite medium. In this case again, the response is a function of properties of constituents and their geometric arrangement. The latter effect is incorporated by introducing the average gas bubble size, $\rho_{b}=V_{g} / S_{g}$, where $V_{g}, S_{g}$ define the volume of gas inclusions and the total surface area of gas-matrix interfaces, respectively. The mathematical details are provided in the same reference as quoted above, i.e., [56].

\section{CONCLUSIONS}

Over the last few decades the research on unsaturated soil has been growing exponentially. The number of researchers engaged in this area is likely to be larger than that in all remaining branches of Soil Mechanics. In view of the arguments presented in this paper, it would seem that research resources being invested in this area are disproportionate and are perhaps mis-directed.

The main conclusions emerging from this work relating to non-expansive unsaturated soils are as follows:

- Experiments on unsaturated soils under constant suction or under constant water content do not yield any additional information on the mechanical response as results can be rationally interpreted within the existing frameworks of soil skeleton behaviour. This has been demonstrated through a number of examples employing the test results published in the literature.

- The experimental set up for testing unsaturated soils at constant suction is such that the samples are unlikely to have homogenous microstructure of saturation. The test results should, therefore, be used with caution.

- Microstructure of saturation plays an important role in defining the mechanical properties of unsaturated soils. Five different types of microstructures have been identified in this paper. Except for microstructure type A, mechanical response for other microstructures of saturation can be defined in terms of properties of soil skeleton, liquids phases and the geometric arrangement of constituents. It should be noted that the approach incorporating suction pressure as an independent state variable does not distinguish between different types of microstructure of saturation.

- Efforts to establish semi-empirical relations for SWRC or an independent relationship between degree of saturation and suction and incorporate them in description of the mechanical behaviour of soils do not appear to be appropriate. It has been demonstrated that these relations are not explicitly required and can be uniquely defined from properties of soil skeleton and phase relationships.

- A rational approach to develop constitutive models for expansive or shrinkable soils is through the framework of chemo-plasticity.

\section{REFERENCES}

[1] Fredlund D.G., Rahardjo H., Soil mechanics for unsaturated soils, John Wiley \& Sons, 1993.

[2] LU N., Likos W.J., Unsaturated soil mechanics, John Wiley \& Sons, 2004.

[3] Murray E.J., Shivkumar V., Unsaturated Soils: A fundamental interpretation of soil behaviour, Wiley-Blackwell, 2010.

[4] CRAig R.F., Soil Mechanics, Chapman \& Hall, 2004.

[5] Barnes G., Soil Mechanics - Principles and practice, Palgrave Macmillan, 2010.

[6] TERZAGHI K.V., The shearing resistance of saturated soils and the angle between the planes of shear, Proceedings of the 1st International Conference on Soil Mechanics and Foundation Engineering, 1936, Vol. 1, 54-56.

[7] LADE P.V., DE BOER R., The concept of effective stress for soil, concrete and rock, Géotechnique, 1997, 47, 61-78

[8] Pietruszczak S., Pande G.N., On the mechanical response of saturated cemented materials - Part I: theoretical considerations, Intern. Journ. Num. Anal. Meth. Geomech., 1995, $19,555-562$.

[9] Pietruszczak S., Turu G., Pande G.N., On the mechanical response of saturated cemented materials, Part II: experimental investigation and numerical simulations, Intern. Journ. Num. Anal. Meth. Geomech., 1995, 19, 563-571.

[10] Nur A., ByerleE J.D., An exact effective stress law for elastic deformation of rock with fluids, Journ. Geophys. Res., 2012, 76, 6414-6419.

[11] Bishop A.W., Blight G.E., Some aspects of effective stress in saturated and partly saturated soils, Géotechnique, 1963, 13, 177-197.

[12] MAšín D., Predicting the dependency of a degree of saturation on void ratio and suction using effective stress principle for unsaturated soils, Intern. Journ. Num. Anal. Meth. Geomech., 2010, 34, 73-90.

[13] Lu N., GodT J.W., Wu D.T., A closed-form equation for effective stress in unsaturated soil, Water Resources Res., 2010, 46, 1-14.

[14] Khalili N., Khabbaz M.H., A unique relationship for $\chi$ for the determination of the shear strength of unsaturated soils, Geotechnique, 1998, 48, 1-7. 
[15] BAKer R., Frydman S., Unsaturated soil mechanics: Critical review of physical foundations, Engineering Geology, 2009, 106, 26-39.

[16] Computers \& Geotechnics, Special Issue on Unsaturated Soils: Models, Algorithms and Applications (eds. A. Gens and D. Sheng), 2008, Vol. 35.

[17] Vadoze Zone Journal, Special Section: Principle of Effective Stress, 2014, Vol. 13(5).

[18] BuCKingham E., Studies on the movement of soil moisture, U.S. Department of Agriculture, Bureau of Soils, 1907, 38.

[19] RichARDS L.A., The usefulness of capillary potential to soil moisture and plant investigators, Journ. Agric. Res., 1928, 37, 719-742.

[20] GARDNER R., A method of measuring the capillary tension of soil moisture over a wide moisture range, Soil Science, 1937, 43, 277-284.

[21] VAN GeNUChTEN M.T., A closed-form equation for predicting the hydraulic conductivity of unsaturated soils, Soil Sci. Soc. Amer. Journ., 1980, 44, 892-898.

[22] Gallipoli D., Constitutive and Numerical Modelling of Unsaturated Soil, Ph.D. Thesis, University of Glasgow, U.K., 2000.

[23] Gallipoli D., Wheeler S.J., Karstunen M., Modelling the variation of degree of saturation in a deformable unsaturated soil, Géotechnique, 2003, 53, 105-112.

[24] Dieudonne A.C., Levasseur S., Charlier R., Della Vecchia G., Jommi C., A water retention model for compacted clayey soils, Proc. ComGeo III (eds. S. Pietruszczak and G.N. Pande), 2013, 1, 23-31. ICEE.

[25] WANG M., PANDE G.N., Kong L.W., Comparison of pore-size distribution of soils obtained by different methods, Intern. Journ. Geomech., 2015 (submitted).

[26] JosA A., Alonso A.E., Loret A., Gens A., Stress-strain behaviour or partially saturated soils, European Conference on Soil Mechanics and Foundation Engineering, Dublin, 1987, Vol. 9, 561-564.

[27] ZAKARIA I., Yielding of unsaturated soil, Ph.D. thesis, University of Sheffield, UK 1995.

[28] SivAKUMAR V., A critical state framework for unsaturated soil, Ph.D. Thesis, University of Sheffield, UK 1993.

[29] Lins A.H.P., Discussion on "An alternative framework for unsaturated soil behaviour" S. J. Wheeler (1991), Géotechnique, 1992, 42, 525-527.

[30] Tarantino A., De Col E., Compaction behaviour of clay, Géotechnique, 2008, 58, No. 3, 199-213.

[31] Tarantino A., Tombolato S., Coupling of hydraulic and mechanical behaviour in unsaturated compacted clay, Geotechnique, 2005, 55, No. 4, 307-317.

[32] GRIFFITHS D.V., LU N., Unsaturated slope stability analysis with steady infiltration or evaporation using elasto-plastic finite elements, Intern. Journ. Num. Anal. Meth. Geomech., 2005, 29, 249-267.

[33] Alonso E.E., Gens A., Josa A., A constitutive model for partially saturated soils, Géotechnique, 1990, 40, 405-430.

[34] TAMAGnini R., An extended Cam-clay model for unsaturated soils with hydraulic hysteresis, Geotechnique, 2004, 54, 223228.

[35] LI X.S., Modelling of hysteresis response for arbitrary wetting/drying paths, Computers and Geotechnics, 2005, 32, 133-137.
[36] NuTH M., Lalou L., Advances in modelling hysteretic water retention curve in deformable soils, Computer and Geotechnics, 2008, 35, 835-844.

[37] Gens A., Alonso E.E., A framework for the behaviour of unsaturated expansive clays, Can. Geotechn. Journ., 1992, 29, 1013-1032.

[38] Pereira J.H., Fredlund D.G., Volume change behavior of collapsible compacted gneiss soil, Journ. Geotech. Geoenviron. Eng., 2000, 126, 907-916.

[39] Lim Y., Miller G., Wetting induced compression of compacted Oklahoma soils, Journ. Geotech. Geoenviron. Eng., 1999, 130, 1014-1023.

[40] Chen Z.H., Fredlund D.G., GAN J.K., Overall volume change, water volume change, and yield associated with an unsaturated compacted loess, Can. Geotech. Journ., 1999, 36, 321-329.

[41] Pietruszczak S., Lydzba D., Shao J.F., Modelling of deformation response and chemo-mechanical coupling in chalk, Int. Journ. Num. Anal. Meth. Geomech., 2006, 30, 997-1018.

[42] HueCKel T., Chemo-plasticity of clays subjected to stress and flow of a single contaminant, Int. Journ. Num. Anal. Meth. Geomech., 1997, 21, 43-72.

[43] Pietruszczak S., Haghighat E., Assessment of slope stability in cohesive soils due to a rainfall, Int. Journ. Num. Anal. Meth. Geomech., 2012, 37, 3278-3292.

[44] Tadepalli R., Fredlund D.G., The collapse behavior of a compacted soil during inundation, Can. Geotech. Journ., 1991, 28, 477-488.

[45] JOTISANKASA A., Collapse behaviour of compacted silty clay, Ph.D. Thesis, Imperial College, London 2005.

[46] Sun D., Sheng D., Xu Y., Collapse behaviour of unsaturated compacted soil with different initial densities, Can. Geotech. Journ., 2007, 44, 673-686.

[47] Wheeler S.J., Sharma R.S., Buisson B.S.R., Coupling of hydraulic hysteresis and stress-strain behaviour in unsaturated soils, Géotechnique, 2003, 53, 41-54.

[48] Rojas E., Chavez O., Volumetric behavior of unsaturated soils, Can. Geotech. Journ., 2013, 50, 209-222.

[49] Li X., Thomas H.R., FAN Y., Finite element method and constitutive modelling and computation for unsaturated soils, Comp. Meth. Appl. Mech. \& Eng., 1999, 169,_135-159.

[50] Pietruszczak S., Pande G.N., On mechanical response of partially saturated soils at low and high degrees of saturation, Numerical Models in Geomechanics, NUMOG V, (eds. G.N. Pande and S. Pietruszczak), 1995, 1, 33-39, Balkema.

[51] Wroth C.P., Houlsby G.T., Soil machanics: property characterization and analysis procedures, Proc. 11th ICSMFE, 1985, Vol. 1, 1-55.

[52] OKUSA S., Wave induced stress in unsaturated marine sediments, Geotechnique, 1985, 35, 517-532.

[53] WhEELER S.J., A conceptual model for soil containing large gas bubbles, Geotechnique, 1988, 38, 397-413.

[54] Bower C.A., Goertzen J.O., Surface area of soils and clays by an equilibrium ethylene glycol method, Soil Sci., 1959, 87, 289-292.

[55] Donaldson E.C., Kendall R.F., BAKer B.A., Surface area measurement of geologic materials, Soc. Petroleum Eng., 1973, 13, 111-116.

[56] Pietruszczak S., Pande G.N., On the mechanics of partially saturated soils, Computers and Geotechnics, 1991, 12, 55-71. 